EXTENDED REPORT

\title{
Urinary bladder cancer in Wegener's granulomatosis: risks and relation to cyclophosphamide
}

\author{
A Knight, J Askling, F Granath, P Sparen, A Ekbom
}

See end of article for authors' affiliations

Correspondence to:

Dr A Knight, Department

of Medicine, Uppsala

University Hospital, SE-

75185 Uppsala, Sweden;

ann.kataja.knight@

akademiska.se

Accepted 19 April 2004

Published online first

6 May 2004

Objective: To assess and characterise the risk of bladder cancer, and its relation to cyclophosphamide, in patients with Wegener's granulomatosis.

Methods: In the population based, nationwide Swedish Inpatient Register a cohort of 1065 patients with Wegener's granulomatosis, 1969-95, was identified. Through linkage with the Swedish Cancer Register, all subjects in this cohort diagnosed with bladder cancer were identified. Nested within the cohort, a matched case-control study was performed to estimate the association between cyclophosphamide and bladder cancer using odds ratios (ORs) as relative risk. In the cohort the cumulative risk of bladder cancer after Wegener's granulomatosis, and the relative prevalence of a history of bladder cancer at the time of diagnosis of Wegener's granulomatosis, were also estimated.

Results: The median cumulative doses of cyclophosphamide among cases $(n=11)$ and controls $(n=25)$ were $113 \mathrm{~g}$ and $25 \mathrm{~g}$, respectively. The risk of bladder cancer doubled for every $10 \mathrm{~g}$ increment in cyclophosphamide (OR=2.0, 95\% confidence interval (Cl) 0.8 to 4.9$)$. Treatment duration longer than 1 year was associated with an eightfold increased risk (OR=7.7, 95\% Cl 0.9 to 69). The absolute risk for bladder cancer in the cohort reached 10\% 16 years after diagnosis of Wegener's granulomatosis, and a history of bladder cancer was (non-significantly) twice as common as expected at the time of diagnosis of Wegener's granulomatosis.

Conclusion: The results indicate a dose-response relationship between cyclophosphamide and the risk of bladder cancer, high cumulative risks in the entire cohort, and also the possibility of risk factors operating even before Wegener's granulomatosis.

S everal studies, including a recent study from our group, have indicated that patients with Wegener's granulomatosis are at increased risk of cancer of the urinary bladder. $^{1-3}$ Studies of patients with malignant diseases treated with cyclophosphamide have indicated an association between cyclophosphamide and the risk of bladder cancer ${ }^{4}$ based on less than 20 bladder cancers. Our present knowledge of bladder cancer risk in relation to cyclophosphamide use in Wegener's granulomatosis rests upon fewer than a dozen cancer cases detected in two limited series of selected patients treated with cyclophosphamide $(\mathrm{n}=145$ and $\mathrm{n}=158$, respectively). ${ }^{12}$ Likewise, reports on other rheumatological conditions are limited to a handful of observed cases of bladder cancer. ${ }^{6-8}$ Because cyclophosphamide has markedly improved survival in Wegener's granulomatosis, and remains the mainstay induction treatment, not only for generalised Wegener's granulomatosis but also for a series of manifestations of more common rheumatological diseases, the prevalence of subjects with a history of cyclophosphamide exposure is likely to increase substantially. It has therefore become increasingly important to assess accurately, and to attribute, the risks associated with cyclophosphamide use.

In this study we aimed at improving the understanding of bladder cancer in Wegener's granulomatosis and, in particular, its association with cyclophosphamide. Firstly, in a case-control study nested within our previously identified population based cohort of 1065 patients with Wegener's granulomatosis, ${ }^{3}$ we assessed the relative risk (odds ratio (OR)) of bladder cancer after exposure to cyclophosphamide. Secondly, we estimated the absolute risk (cumulative incidence) of bladder cancer after diagnosis of Wegener's granulomatosis in the entire cohort of 1065 patients. Thirdly, we estimated the prevalence of a previous diagnosis of bladder cancer in the cohort already at the time of diagnosis of Wegener's granulomatosis relative to that expected in the corresponding general population.

\section{SUBJECTS AND METHODS}

In Sweden, inpatient care is public, population based, and referrals are based on geography rather than financial capacity. The underlying cohort of patients with Wegener's granulomatosis was identified in the population based and nationwide Swedish Inpatient Register that includes subject data on all inpatient care in Sweden, county wide since 1964, nationwide since 1987. ${ }^{9}$ In this register we identified all patients discharged with Wegener's granulomatosis (International Classification of Diseases, version $8=446.2$ 1968-1986), version 9=446E 1987-1996) between 1969 and 1994-in total, 1065 subjects. Through linkage of the cohort to the Swedish Cancer Register (which has a completeness of $98 \%$ resulting from mandatory reporting of all diagnosed cancers by clinicians and pathologists), ${ }^{10}$ we identified a total of 23 subjects in the cohort who at some time between 1958 and 1995 had been diagnosed with a bladder cancer. Each bladder cancer case was then matched with three controls from the same cohort. The controls were matched for sex and age at diagnosis of Wegener's granulomatosis, and the controls had to be alive on the date at which bladder cancer was diagnosed in the cases. All medical records of cases and controls were reviewed, and data including date of symptoms of Wegener's granulomatosis, accumulated cyclophosphamide dose, duration of cyclophosphamide treatment, other treatments and, whenever possible, information on smoking 
Table 1 Characteristics of cases with bladder cancer diagnosed after diagnosis of Wegener's granulomatosis in a population based cohort of 1065 patients with Wegener's granulomatosis in Sweden, 1969-94

\begin{tabular}{|c|c|c|c|c|c|c|c|c|c|}
\hline Year of birth & Sex & $\begin{array}{l}\text { Age at } \\
\text { WG }\end{array}$ & $\begin{array}{l}\text { Age at } \\
\text { cancer }\end{array}$ & $\begin{array}{l}\text { Time from WG } \\
\text { to cancer } \\
\text { (months) }\end{array}$ & $\begin{array}{l}\text { Time from } \mathrm{CY} \\
\text { to cancer* } \\
\text { (months) }\end{array}$ & $\begin{array}{l}\text { Cumulative } \\
\text { dose of } \mathrm{CY} \\
\text { (g) }\end{array}$ & $\begin{array}{l}\text { Duration of } \\
\text { CY } \\
\text { (months) }\end{array}$ & Bladder cancer & Smoking status \\
\hline 1913 & $M$ & 73 & 77 & 57 & $0+$ & 108 & 86 & Non-invasive & Ex-smoker \\
\hline 1915 & $M$ & 58 & 66 & 96 & - & - & 96 & Non-invasive & No information \\
\hline 1915 & $M$ & 66 & 80 & 168 & 163 & 23 & 5 & Non-invasive & No information \\
\hline 1910 & $M$ & 75 & 83 & 103 & 101 & 115 & 98 & Invasive & Never smoker \\
\hline 1922 & $M$ & 68 & 73 & 70 & 14 & 178 & 56 & Invasive & Never smoker \\
\hline 1926 & $M$ & 55 & 63 & 98 & 0 & 234 & 98 & Non-invasive & Ex-smoker \\
\hline 1933 & $M$ & 41 & 56 & 180 & 2 & 224 & 178 & Invasive & Never smoker \\
\hline 1933 & $M$ & 47 & 62 & 180 & 67 & 140 & 53 & Non-invasive & Ex-smoker \\
\hline 1900 & $\mathrm{~F}$ & 74 & 78 & 48 & - & 0 & 0 & Invasive & Never smoker \\
\hline 1909 & $\mathrm{~F}$ & 70 & 74 & 51 & 1 & 54 & 50 & Non-invasive & No information \\
\hline 1942 & $\mathrm{~F}$ & 40 & 51 & 125 & 31 & 110 & 108 & Non-invasive & Never smoker \\
\hline
\end{tabular}

WG, Wegener's granulomatosis; $\mathrm{CY}$, cyclophosphamide.

*Time from stopping CY treatment to appearance of bladder cancer; this patient continued to receive cyclophosphamide even after the diagnosis of bladder cancer was made-that is, CY was never discontinued.

habits, was abstracted. All cases and controls were evaluated to assess if they met the American College of Rheumatology (ACR) criteria for the diagnosis of Wegener's granulomatosis, and patients for whom the diagnosis could not be confirmed were excluded. Likewise, patients for whom the bladder cancer diagnosis could not be confirmed by the medical files and pathology reports were excluded.

Of the 23 registered bladder cancer cases within the cohort, 14 had developed bladder cancer after the first discharge listing Wegener's granulomatosis. Three of these cases had to be excluded as they either did not meet the ACR criteria for Wegener's granulomatosis (one had giant cell arteritis and one pulmonary fibrosis) or because the medical file could not be retrieved (one case), leaving 11 confirmed incident bladder cancer cases in subjects with a confirmed diagnosis of Wegener's granulomatosis. One of these cases had a history of chronic cystitis. Of the 33 controls selected for the 11 incident bladder cancer cases, the diagnosis of Wegener's granulomatosis could be confirmed in 25: complete medical files could not be found in four controls, and another four controls turned out to have other vasculitic conditions (unspecified vasculitic disease, rheumatic polymyalgia, alveolitis, and polyarteritis nodosa, respectively). The nested casecontrol study thus consisted of 11 cases with Wegener's granulomatosis and bladder cancer (table 1), and 25 controls with Wegener's granulomatosis but no bladder cancer. The median age at diagnosis of Wegener's granulomatosis diagnosis among cases and controls was 67 and 68 years, respectively. Eight of 11 (73\%) cases had kidney disease compared with 15/25 (60\%) controls. Eight of the 11 cases $(73 \%)$ had generalised Wegener's granulomatosis (defined as kidney or lung disease, or both) and three had limited disease (ear, nose, and throat involvement only, or otherwise limited disease not affecting the lung/kidney). Seventeen of the 25 $(68 \%)$ controls had generalised disease and eight had limited disease. All patients had received varying doses of steroids. Other treatments included azathioprine, plasmapheresis, cyclosporin A, chlorambucil, and intravenous immunoglobulins. One of the controls had received irradiation therapy only. Information on smoking habits was present in the medical files of eight cases and 18 controls.

In the remaining nine $(23-14)$ subjects with a diagnosis of bladder cancer, the bladder cancer diagnosis had been made before the diagnosis of Wegener's granulomatosis. One of these nine cases had to be excluded, as the bladder cancer diagnosis could not be confirmed by the pathology report, leaving eight confirmed prevalent cases of bladder cancer at the time of the first discharge listing Wegener's granulomatosis.

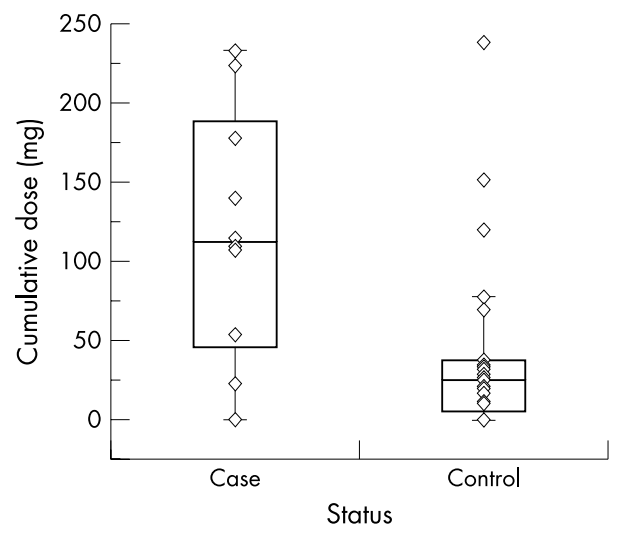

Figure 1 Distribution of the cumulative dose of cyclophosphamide among the 11 cases and their 25 controls in the case-control study nested in a population based cohort of 1065 patients with Wegener's granulomatosis. (Wilcoxon $\mathrm{p}$ for difference $=0.01$ ).

\section{Statistics}

In the nested case-control study we estimated relative risks as ORs (and 95\% confidence intervals (CIs)) for the association between cyclophosphamide and bladder cancer using conditional logistic regression in PROC PHREG in SAS. ${ }^{11}{ }^{12}$ All models were adjusted for smoking and age (linear, to decrease residual confounding). Cyclophosphamide exposure was treated both as a continuous variable (cumulative dose in grams) and as a categorical variable (dichotomised according to the median cumulative dose among the controls).

In the assessment of the cumulative risk of bladder cancer in the entire cohort, we calculated the incidence proportion

Table 2 Adjusted* odds ratios (OR, including 95\% confidence interval (CI)) for bladder cancer associated with cyclophosphamide use in Swedish patients with Wegener's granulomatosis

\begin{tabular}{ll}
\hline Variable & OR $(95 \% \mathrm{Cl})$ \\
\hline Cumulative dose $($ per $10 \mathrm{~g})$ & $2.0(0.8$ to 6.9$)$ \\
Cumulative dose $<5 \mathrm{~g}$ & 1.0 (reference) \\
Cumulative dose $\geqslant 25 \mathrm{~g}$ & $5.2(0.8$ to 36$)$ \\
Duration of treatment (per year) & $1.1(1.0$ to 1.3$)$ \\
Duration of treatment $<1$ year & 1.0 (reference) \\
Duration of treatment $\geqslant 1$ year & $7.7(0.9$ to 69$)$ \\
\hline${ }^{*}$ Adjusted for age (linear) and smoking (ever $v$ other).
\end{tabular}


("absolute risk") of bladder cancer by the time of follow up using the product limit method in PROC PHREG in SAS. ${ }^{12}$

In the assessment of the relative prevalence of bladder cancer in subjects newly diagnosed with Wegener's granulomatosis, we calculated the ratio between the observed prevalence of bladder cancer in the cohort at the time of diagnosis of Wegener's granulomatosis and that expected in the general population. For each of the 1065 patients in the source cohort, the expected prevalence was calculated as the sex, birth year, and calendar period specific prevalence of registered bladder cancer in the general population, counting from 1958 to the first date of discharge with Wegener's granulomatosis. Because all subjects in the cohort with Wegener's granulomatosis were alive at entry, the subjectspecific expected prevalence was further adjusted to remove bladder cancer cases that were fatal during the period 1958 until the date of entry into the cohort for that subject. The observed prevalence in the cohort was then divided by the sum of the subject-specific expected prevalence.

\section{RESULTS \\ Cyclophosphamide and risk of bladder cancer after Wegener's granulomatosis}

Ten of the eleven cases $(91 \%)$ were exposed to cyclophosphamide (the eleventh case had been treated with chlorambucil and azathioprine). Twenty of the 25 (80\%) controls were exposed to cyclophosphamide. None of the cases but three of the controls had received intravenous cyclophosphamide (together with mesna), but only in addition to oral cyclophosphamide. No other controls, and none of the cases, had received mesna. The median cumulative dose of cyclophosphamide among cases was $113 \mathrm{~g}$, compared with $25 \mathrm{~g}$ among the controls (fig 1, Wilcoxon $\mathrm{p}$ for difference $=$ $0.01)$. The median duration of treatment among the cases was 86 months ( 7 years and 2 months) compared with 13 months among the controls.

Each $10 \mathrm{~g}$ increment in cumulative dose of cyclophosphamide was associated with a doubled risk of bladder cancer $(\mathrm{OR}=2.0,95 \%$ CI 0.8 to 4.9 ; table 2 ). Similarly, cumulative doses above (versus below) the median among controls $(25 \mathrm{~g})$ were associated with a fivefold increase in risk of bladder cancer ( $\mathrm{OR}=5.2,95 \% \mathrm{CI} 0.8$ to 36$)$. There was also a tendency towards an increased risk of bladder cancer with increasing duration of treatment, with a $10 \%$ increase in risk for each month receiving cyclophosphamide $(\mathrm{OR}=1.1$, 95\% CI 1.0 to 1.3). Likewise, exposure to cyclophosphamide for longer than 13 months (median among the controls) was associated with a near eightfold increased risk ( $\mathrm{OR}=7.7$, 95\% CI 0.9 to 69). Adjustment for smoking had a modest effect on the above risk estimates, and smoking itself did not emerge as a strong risk factor in the models (data not shown).

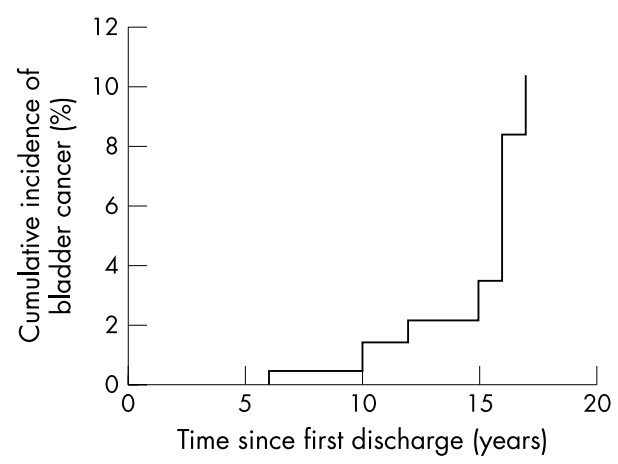

Figure 2 Cumulative incidence of bladder cancer by time since first discharge for Wegener's granulomatosis.

\section{Cumulative risk of bladder cancer after Wegener's granulomatosis}

Starting at $0 \%$ at the time of the first discharge with Wegener's granulomatosis, the cumulative risk of bladder cancer was $2 \%$ (95\% CI 0.1 to 3.9 ) after 10 years of follow up, but increased to $10 \%$ (95\% CI 2.7 to 17 ) after 16 years since the first discharge (fig 2). The time from diagnosis of Wegener's granulomatosis to diagnosis of bladder cancer varied between 4 and 15 years, and the latency from stopping cyclophosphamide treatment to diagnosis of bladder cancer varied between 0 and 14 years, with a median latency time of 2 years and 7 months.

\section{History of bladder cancer in patients newly diagnosed with Wegener's granulomatosis}

Eight of 1065 patients had developed bladder cancer before the diagnosis of Wegener's granulomatosis. Compared with the expected prevalence of bladder cancer in Sweden $(0.4 \%)$, this corresponded to a relative risk of 2.1 (95\% CI 0.6 to 3.6). These patients had not been subjected to treatment with cyclophosphamide for any other disease. Six or more of these eight patients $(75 \%)$ were current or ex-smokers. None of these bladder cancers was treated with complete cystectomy. All patients subsequently developed generalised Wegener's granulomatosis, at a median of 1.5 years after the diagnosis of bladder cancer. All eight patients received oral cyclophosphamide.

\section{DISCUSSION}

The results of our study suggest that cyclophosphamide in dosages fully comparable to those often encountered in clinical practice is associated with a dose-response increase in the relative risk of bladder cancer among patients with Wegener's granulomatosis. The cumulative risk of bladder cancer in these patients is alarmingly high. These bladder cancers appear without connection to haemorrhagic cystitis, and the two conditions may not arise from the same mechanisms. In contrast, Wegener's granulomatosis and bladder cancer may have some aetiological factors in common.

Cyclophosphamide is a commonly used drug in the treatment of malignant diseases-for example, as part of the CHOP regimen used for malignant lymphomas. In the management of inflammatory rheumatic diseases cyclophosphamide has proved to be highly effective and remains the standard treatment of serious extra-articular manifestations of rheumatoid arthritis, lung, central nervous system, and kidney manifestations of lupus, and for vasculitides such as Wegener's granulomatosis. Because of the implementation of cyclophosphamide as first line induction treatment ${ }^{13}$ in the above conditions, the prevalence of subjects ever exposed to cyclophosphamide in doses similar to those of the present study is increasing.

Despite indications of malignant side effects in the urinary bladder, ${ }^{4}{ }^{6}$ surprisingly few studies have assessed the risk of bladder cancer after exposure to cyclophosphamide (table 3 ). Indeed, our risk assessment today rests upon a few observed cases in non-population based studies. In the hitherto largest study, 145 patients with Wegener's granulomatosis identified at a tertiary referral centre were followed up. The seven cases of bladder cancer observed corresponded to a 31-fold relative risk and a cumulative risk of $5 \%$ at 10 years and $10 \%$ at 15 years. ${ }^{1}$ In our cohort, the relative risk of bladder cancer was fivefold, ${ }^{3}$ and the cumulative risk was $2 \%$ after 10 years, but increased to $10 \%$ after 16 years, which should be compared with a lifetime risk of bladder cancer below $2 \%$ in Sweden. ${ }^{14}$ Our results further indicate a dose-response relationship between cyclophosphamide and bladder cancer risk, with particularly high relative risks for treatments 
Table 3 Published studies of bladder cancer risk in subjects treated with cyclophosphamide

\begin{tabular}{|c|c|c|c|c|c|c|}
\hline Diagnosis & $\begin{array}{l}\text { Patients } \\
\text { (n) }\end{array}$ & $\begin{array}{l}\text { Cumulative dose of } \\
\text { CY for patients (g) } \\
\text { Median (range) }\end{array}$ & $\begin{array}{l}\text { Bladder } \\
\text { cancers } \\
\text { (n) }\end{array}$ & Relative risk & Cumulative risk (follow up) & Reference \\
\hline $\mathrm{NHL}$ & 6171 & $37(9-146)$ & 9 & 4.5 & Not stated & Travis et al $(1995)^{4}$ \\
\hline NHL & 471 & $104(27-148)$ & 7 & 6.8 & $3.5 \%$ (8 yrs) $11 \%$ (12 yrs) & Pedersen-Bjergaard et al $(1988)^{5}$ \\
\hline SLE & 1585 & Not stated & 5 & 1.6 & Not stated & Mellemkjaer et al (1997) \\
\hline SLE/RA & $43 / 11$ & $46 / 56(2-152)$ & $1 / 1$ & Not stated & Not stated & Plotz et al (1979) ${ }^{6}$ \\
\hline RA & 119 & $63(18-108)$ & 6 & & $5 \%$ (11 yrs) & Baker et al $(1987)^{22}$ * \\
\hline RA & 119 & 120 (mean dose) & 9 & 22 & Not stated & Radis et al $(1995)^{23}$ * \\
\hline MS & 70 & $61(38-93)$ & 5 & & $5.7 \%$ (not stated) & de Ridder et al (1998) \\
\hline WG & 145 & $144(19-251)$ & 7 & 31 & $5 \%(10$ yrs $)$ & Talar-Williams $(1996)^{1}$ ** \\
\hline WG & 158 & Not stated & 4 & 33 & Not stated & Hoffman et al $(1992)^{2} * *$ \\
\hline WG & 111 & $101(5-531)$ & 3 & & $2.7 \%$ (20 yrs) & Stillwell et al $(1988)^{25}$ \\
\hline WG & 1065 & $113(0-234)$ & 11 & 4.8 & $10 \%$ (16 yrs) & Present study \\
\hline
\end{tabular}

CY, cyclophosphamide; NHL, non-Hodgkin's lymphoma; RA, rheumatoid arthritis; SLE, systemic lupus erythematosus; WG, Wegener's granulomatosis. * and ** indicate studies with overlapping or identical study groups.

lasting longer than 1 year or cumulative doses above $25 \mathrm{~g}$. Although recent reports ${ }^{15}$ indicate that the duration of cyclophosphamide treatment may be reduced, cumulative doses above $25 \mathrm{~g}$ (for example, as two 3 month cycles of oral cyclophosphamide) will remain a common finding.

Only one of our cases had undergone cystoscopy (which revealed a chronic cystitis) earlier in the disease course, 11 years before the diagnosis of bladder cancer. The other cases were examined because of haematuria (macro- or microscopic) only immediately before the cancer diagnosis. Haemorrhagic cystitis (microscopic) is known to have occurred in 18 of the 25 controls. This observation, which is in keeping with those of Talar-William and PedersenBjergaard, ${ }^{15}$ suggests that haemorrhagic cystitis does not precede cyclophosphamide associated bladder cancer, and that the mechanisms leading to haemorrhagic cystitis and bladder cancer may not be the same. The cytotoxic properties of the cyclophosphamide metabolite acrolein cause haemorrhagic cystitis and can be protected against by mesna. ${ }^{16}$ The carcinogenic effects, however, are more likely to be mediated through molecular changes caused by the alkylating properties of cyclophosphamide, such as mutations in the p53 tumour suppressor gene. ${ }^{17-19}$ If so, haemorrhagic cystitis would not be a good marker of the increased risk of bladder cancer, nor would mesna be cancer preventive. Instead, other measures would be required to reduce the cancer risk associated with cyclophosphamide.

Although our results are not formally significant, they point to the possibility of an increased risk of bladder cancer even before the diagnosis of Wegener's granulomatosis, in turn suggesting shared aetiologies or risk factors for bladder cancer and Wegener's granulomatosis. The possible relationship between a cancer diagnosis and Wegener's granulomatosis has also been demonstrated in a study by Tatsis et al, ${ }^{20}$ who found an increased risk for renal cell carcinoma in patients who later, or simultaneously, developed Wegener's granulomatosis. In our previous study of cancer risk in a large population based cohort of Wegener's granulomatosis ${ }^{3}$ we found that the risk for renal cell carcinoma was almost doubled, but we did not study the time relation between the diseases.

Smoking is a strong risk factor for bladder cancer and could be one such shared aetiological factor, although we are unaware of studies linking Wegener's granulomatosis to smoking. In our nested case-control study, smoking did not emerge as a strong risk factor, nor did it materially confound the association with cyclophosphamide; but the information on smoking was scarce, and these results should be interpreted with caution.
The strength of our nested case-control study lies in the population based and nationwide setting of the source cohort, which is the hitherto largest identified cohort of patients with Wegener's granulomatosis, the follow up of which extended up to 26 years. All subjects included in the analyses of this study had their diagnoses of Wegener's granulomatosis and bladder cancer confirmed by a manual review of their medical records. The diagnosis of Wegener's granulomatosis has also previously been validated ${ }^{3}$ against the ACR criteria, and we found a validity of about $88 \%$ in the diagnosis, therefore we do not think other vasculitic diseases have influenced these data. Further, the identification of bladder cancers was independent of the exposure and the diagnosis of Wegener's granulomatosis, and most likely to be complete. Our study also observed the largest number of bladder cancers in an assessment of bladder cancer risk after cyclophosphamide exposure (table 3). However, the power of the study was limited and several risk estimates did not reach beyond borderline significance. The fact that all patients had at some stage been admitted to hospital owing to Wegener's granulomatosis is unlikely to affect the validity of our results, especially because the overwhelming majority of patients with Wegener's granulomatosis in Sweden are diagnosed or treated as inpatients. Accordingly, we also found that all patients had been diagnosed with Wegener's granulomatosis within a year of first admission to hospital, most of them during this admission. The possibility of surveillance bias cannot be excluded, as a patient with Wegener's granulomatosis has regular medical examinations over many years. However, in this study, only one of the bladder cancer cases had had a chronic cystitis verified by cystoscopy long before the bladder cancer diagnosis. Among the diagnosed bladder cancers, 5/14 were invasive already at diagnosis, and six of the patients with bladder cancer died with bladder cancer noted on the death certificate, suggesting that early detection was not the case.

In conclusion, patients with Wegener's granulomatosis are at a markedly increased risk of bladder cancer, with absolute risks as high as $10 \%$ some years after diagnosis. Our study indicates that this increased risk may partly be attributed to cyclophosphamide, but also that other factors even before the diagnosis of Wegener's granulomatosis may be of importance. The results also indicate that measures to prevent haemorrhagic cystitis may not necessarily decrease the risk of bladder cancer. To avoid an accumulating number of cyclophosphamide related bladder cancers, sustained clinical attention should be directed towards patients with a history of cyclophosphamide exposure and the presence of other, possibly avoidable, risk factors for bladder cancers in these patients. 


\section{Authors' affiliations}

A Knight, Department of Rheumatology, Akademiska University

Hospital, Uppsala, Sweden

J Askling, F Granath, A Ekbom, Clinical Epidemiology Unit, Department of Medicine, Karolinska Hospital, Stockholm, Sweden

J Askling, Rheumatology Unit, Department of Medicine, Karolinska

Hospital, Stockholm, Sweden

P Sparen, Department of Medical Epidemiology, Karolinska Institutet, Stockholm, Sweden

\section{REFERENCES}

1 Talar-Williams C, Hijazi YM, Walther MM, Linehan M, Hallahan CW, Lubensky I, et al. Cyclophosphamide-induced cystitis and bladder cancer in patients with Wegener's granulomatosis. Ann Intern Med 1996;124:477-84.

2 Hoffman GS, Kerr GS, Leavitt RY, Hallahan CW, Lebovics RS, Travis WD et al. Wegener's granulomatosis: an analysis of 158 patients. Ann Intern Med 1992;116:488-98.

3 Knight A, Askling J, Ekbom A. Cancer incidence in a population-based cohort of patients with Wegener's granulomatosis. Int J Cancer 2002;100:82-5.

4 Travis LB, Curtis RE, Glimelius B, Holowaty EJ, Van Leeuwen FE, Lynch CF, et al. Bladder and kidney cancer following cyclophosphamide therapy for non-Hodgkin's lymphoma. J Nat Cancer Inst 1995;87:524-30.

5 Pedersen-Biergaard J, Ersboll J, Hansen VL, Sörensen BL, Christoffersen K, Hou-Jensen $\mathrm{K}$, et al. Carcinoma of the urinary bladder after the treatment with cyclophosphamide for non-Hodgkins lymphoma. N Engl J Med 1988;318:1028-32

6 Plotz PH, Klippel JH, Decker JL, Grauman D, Wolff B, Brown BC, et al. Bladder complications in patients receiving cyclophosphamide for systemic lupus erythematosus or rheumatoid arthritis. Ann Intern Med 1979:91:221-3.

7 Beauparlant P, Papp K, Haraoui B. The incidence of cancer associated with the treatment of rheumatoid arthritis. Semin Arthritis Rheum 1999;29:148-58.

8 Ansher AF, Melton JW 3rd, Sliwinski AJ. ladder malignancy in a patient receiving low dose cyclophosphamide for treatment of rheumatoid arthritis. Arthritis Rheum 1983;26:804-5.

9 Socialstyrelsen. Patientregistret. Quality and content. Stockholm: Socialstyrelsen, 1987-96.

10 Mattsson B, Wallgren A. Completeness of the Swedish Cancer Register. Nonnotified cancer cases recorded on death certificates in 1978. Acta Radio Oncol 1984;23:305-13.
11 Breslow NE, Day NE. Statistical methods in cancer research. Volume II. The design and analysis of cohort studies. IARC Sci Publ 1987;82:1-406.

12 Cary. Changes and enhancements through release 6.12. SAS Institute Inc. SAS/STAT Software 1997:247-348.

13 Fauci A, Haynes BF, Katz P, Wolff SM. Wegener's granulomatosis: prospective clinical and therapeutical experience with 85 patients for 21 years. Ann Intern Med 1983;98:76-85.

14 Centre for Epidemiology NBoHaW. Cancer Incidence in Sweden, 2001 http://www.sos.se/epc (accessed 11 July 2004).

15 Jayne D, Rasmussen N, Andrassy K, Bacon P, Cohen Tervaert JW Dadoniene $\mathrm{J}$, et al. A randomized trial of maintenance therapy for vasculitis associated with antineutrophil cytoplasmic autoantibodies. N Engl J Med 2003;349:36-44

16 Cox P. Cyclophosphamide cystitis-identification of acrolein as the causative agent. Biochem Pharmacol 1979:28:2045-9.

17 Brandau S, Böhle A. Bladder cancer. Eur Urol 2001;39:491-7.

18 Fernandes ET, Manivel JC, Reddy PK, Ercole CJ. Cyclophosphamide associated bladder cancer-a highly aggressive disease: Analysis of 12 cases. J Urol 1996;156:1931-3.

19 Khan MA, Travis LB, Lynch CF, Soini Y, Hruszkewycz AM, Delgado RM, et al. p53 mutations in cyclophosphamide-associated bladder cancer. Cancer Epidemiol Biomarkers Prev 1998;7:397-403.

20 Tatsis E, Reinhold-Keller E, Steindorf K, Feller AC, Gross WL. Wegener's granulomatosis associated with renal cell carcinoma. Arthritis Rheum 1999;42:751-6.

21 Mellemkjaer L, Andersen V, Linet MS, Gridley G, Hoover R, Olsen JH. NonHodgkin's lymphoma and other cancers among a cohort of patients with systemic lupus erythematosus. Arthritis Rheum 1997:40:761-8.

22 Baker GL, Kahl LE, Zee BC, Stolzer BL, Agarwal AK, Medsger TA. Malignancy following treatment of rheumatoid arthritis with cyclophosphamide. Am J Med 1987;83:1-9

23 Radis CD, Kahl LE, Baker GL, Wasko MCM, Cash JM, Gallatin A, et al. Effects of cyclophosphamnide on the delelopment of malignancy and on long term survival of patients with rheumatoid arthritis. Arthritis Rheum 1995:38:1 120-7.

24 De Ridder D, van Poppel H, Demonty L, D'Hooghe B, Gonsette R, Carton H, et al. Bladder cancer in patients with multiple sclerosis treated with cyclophosphamide. J Urol 1998;159:1881-4.

25 Stillwell TJ, Benson RC Jr, DeRemee RA, McDonald TJ, Weiland LH. Cyclophosphamide-induced bladder toxicity in Wegener's granulomatosis. Arthritis Rheum 1988;31:465-70. 